\title{
EMBO panel gives biology in Finland a pat on the back ...
}

[HELSINKI] Molecular biology and biotechnology research in Finland has been given a glowing report in a study by the European Molecular Biology Organization (EMBO), which attributes much of this success to the creation of a multidisciplinary centres-ofexcellence programme.

Although the study, organized by the Finnish Medical Research Council and completed last month, points out that the fruits of the biotechnology effort have not yet been translated into industrial products, it says investments have so far been used wisely and that this should eventually pay off.

But the report also argues that, in order to perform optimally in future, Finland needs to develop expertise in bioinformatics and structural biology. It argues that the country needs a transgenic-mouse facility to allow its immunologists to achieve cutting-edge science. It also criticizes structural failures in Finland's training and research policies; most problematic, it says, is the low percentage of total research funds allocated competitively.

The main goal of the study was to evaluate the effectiveness of a major effort to promote molecular biology and biotechnology which took place between 1988 and 1995 , at a cost of about FM480 million ( $\$ 104$ million). The EMBO review, which was coordinated by Lennart Phillipson, former head of the Heidelberg-based European Molecular Biology Laboratory, included an assessment of the work of 1,400 academic

\section{... as privatization windfall fills research coffers}

[HELSINKI] Finland is to use

the proceeds from the privatization of a series of state-owned companies related to the chemical, pulp and paper, and heavy metal industries to increase its research budget by 25 per cent over the next three years. The move will make it one of the biggest spenders on research in proportion to its size in the world.

Alongside a predicted continuation of the current trend towards more industrial financing of research, the extra money is expected to raise Finland's spending on research and development to 2.9 per cent of gross national product - at a time when the country's overall budget is being cut back.

According to the minister of education, science and culture, OlliPekka Heinonen, the windfall, worth a total of FM3 billion (US $\$ 650$ million), will not remain a one-off injection of funds. He says the government is committed to maintaining the level of increase after 2000.

The decision substantially to increase spending on science is part of the Finnish government's efforts to strengthen the national economy and reduce unemployment through greater industrial innovation. As such, the money is already earmarked for pursuing strategic aims.

The cash is to be split 40:60 between science and technology. Half of the 40 per cent share allocated to science will go to the Academy of Sciences, Finland's main grant-giving body for basic science, to be distributed within four main priority areas.

Most of the academy's money will be used to extend and strengthen a special programme, launched in 1993, that provides generous support for multidisciplinary university research groups designated by the academy as 'centres of excellence'. Four of the current 17 centres of excellence conduct research in biotechnology and molecular biology.

The rest of the money will be used to develop the academy's new postdoctoral fellowship and graduate school programmes, and to promote the internationalization of Finnish science. The latter category includes promoting participation in the European Union's Framework research programmes, as well as collaborating with the

neighbouring Baltic states and with Russia.

The other half of science's share of the windfall will go directly to Finland's 20 universities. This money will be used to upgrade equipment, increase the number of student places in strategic areas such as electronics, and expand graduate school programmes.

The cash injection continues a trend of rapid growth in Finnish research spending since the early 1980s. Apart from a few lean years during the general recession of the early 1990 s, Finland has experienced the fastest growth in expenditure on research and development - both by the government and by industry - among members of the Organization for Economic Cooperation and Development.

At the same time as increasing research spending, the government will, through the Academy of Sciences, carry out an evaluation of all research activities in Finland, in order to establish how money should be distributed in future. This report on the state of Finnish research will be published later this year.

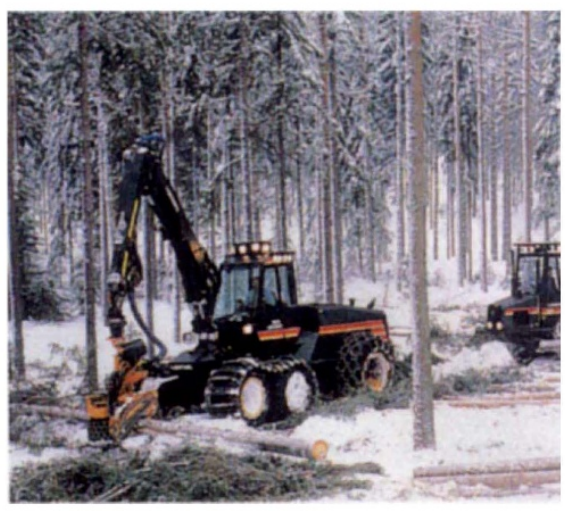

Down to the woods: natural resources have underpinned biotechnology research in Finland.

researchers in 175 different groups.

While praising the country's scientific achievements, the report points out that Finnish scientists are subject to too many evaluations - every year or so on average from different bodies. "This is pointless and a distraction to scientists who must respond to such reviews instead of devoting most of their time to their research efforts," it says. The situation is exacerbated by a quirk in the law which means an academy can provide grants only for one year.

It also says there are too many graduate students and too few postdoctoral positions, and training is too long. The average age of $\mathrm{PhD}$ completion is between 30 and 35 , when scientists are no longer eligible for many postdoctoral fellowships and are often less mobile because they have started families.

Olli-Pekka Heinonen, the minister of education, science and culture, says the government is aware of the shortcomings in the Finnish research structure highlighted by the EMBO report, and is attempting to correct them. "We may have been a little overenthusiastic about evaluating everything," he admits, adding that some relief may be in sight, as the law on research grants has now been changed to allow an academy to give longer-term awards, up to three years.

Heinonen also says that the government intends the new research funds to be allocated as far as possible through competition, and that it is studying ways of lowering the age of $\mathrm{PhD}$ completion.

Finnish scientists say they are pleased with the conclusion of the EMBO evaluation, which they hope will encourage the government to continue to provide generous funding for biotechnology.

"No-one knows exactly what the evaluation will develop into," says Mart Saarma, director of the University of Helsinki's Institute of Biotechnology, a centre of excellence that undergoes evaluations at least once a year. "But it will certainly be taken seriously, not least because it was conducted by an international panel selected independently by EMBO." Saarma says that small countries like Finland are particularly sensitive to the opinion of the outside world.

Alison Abbott 